DOI 10. 18307/2017. 0616

(C) 2017 by Journal of Lake Sciences

\title{
北运河水系底栖动物群落结构与水环境质量评价”
}

\author{
顾晓旳 ${ }^{1,2}$, 徐宗学 ${ }^{2 * *}$, 王 汨 $^{1}$, 殷旭旺 ${ }^{1}$, 刘麟菲 ${ }^{2}$, 张 欣 ${ }^{1,2}$, 左德鹏 ${ }^{2}$ \\ (1: 大连海洋大学水产与生命学院, 辽宁省水生生物重点实验室, 大连 116023) \\ (2: 北京师范大学水科学研究院, 水沙科学教育部重点实验室, 北京 100875 )
}

\begin{abstract}
摘 要: 为全面了解北运河水系的底栖动物群落结构和水环境质量, 于 2015 年 5 月对北运河水系 33 个样点的底栖动物 和水体理化性质进行了调查, 分别采用综合水质标识指数法和底栖动物 $B I$ 指数法对北运河水系进行水质评价, 并通过 Kolmogorov-Smirnov 检验判断正态性, 用 Pearson 相关分析方法对两种评价结果进行比较和分析. 结果表明: 北运河水系共 采集到底栖动物 23 种, 隶属于 3 门 纲 6 目 11 科 11 属, 以水生昆虫和软体动物为主, 整个水系底栖动物群落结构单一; 底栖动物 $B I$ 指数法的评价结果显示, $72 \%$ 的采样点水质为中污染 $(\mathrm{IV})$ 或重污染 $(\mathrm{V})$; 综合水质标识指数法的评价结果 显示, 超过 $57 \%$ 的采样点水质为 IV 类及以下; 根据 K-S 检验, 两组评价得分均符合正态分布; Pearson 相关分析显示两种评 价结果呈显著正相关. 两种评价结果总体上呈现出相同的趋势, 均显示北运河水系整体水质状况较差, 干流水质状况优 于支流, 上游水质状况优于下游, 温榆河上游、坝河下游、通惠河上游和凉水河的水质状况较差, 温榆河源头和坝河上游 的水质状况较好. 两种评价结果在个别点位存在一定差异, 具体表现为基于水体理化因子的评价结果稍优于水质生物评 价结果, 造成这种差异的原因是两种评价方法在时空尺度上存在差异. 针对城市化水平较高、人类活动干扰较强的北运 河水系,同时采用这两种评价方法有助于全面了解其复杂的水环境质量.
\end{abstract}

关键词: 底栖动物; 群落结构; $B I$ 指数; 综合水质标识指数;水环境质量评价; 北运河

\section{Macroinvertebrates community structure and water quality assessment in the North Canal River Basin, Beijing, China}

GU Xiaoyun ${ }^{1,2}$, XU Zongxue ${ }^{2 * *}$, WANG Mi ${ }^{1}$, YIN Xuwang ${ }^{1}$, LIU Linfei ${ }^{2}$, ZHANG Xin ${ }^{1,2}$ \& ZUO Depeng ${ }^{2}$

(1: Liaoning Provincial Key Laboratory for Hydrobiology, College of Fisheries and Life Science, Dalian Ocean University, Dalian 116023, P.R.China)

(2: Key Laboratory of Water and Sediment Science, Ministry of Education, College of Water Sciences, Beijing Normal University, Beijing 100875, P.R.China)

Abstract: Macroinvertebrates as a biological indicator of aquatic health condition plays an important role in the protection and management of water ecological environment. Macroinvertebrates and water quality were investigated on the basis of samples collected at 33 sampling sites in the North Canal River Basin in May 2015. The community structure of macroinvertebrates was analyzed. The comprehensive water quality identification index and Biotic Index of macroinvertebrates were used to assess the water quality in the North Canal River Basin. The results obtained by using these two methods were compared each other by using the KolmogorovSmirnov test and Pearson correlation analysis. In this study, a total of 23 species of macroinvertebrates belonging to 3 phylum, 4 class, 6 order, 11 family and 11 genera were identified in the North Canal River Basin, which mainly represented by aquatic insects and molluscs. The community structure of macroinvertebrates in the whole basin was simple. The result of Biotic Index showed that $72 \%$ of the sampling sites were moderately ( IV ) or seriously ( V ) polluted and comprehensive water quality identification index showed that more than $57 \%$ of the sampling sites were worse than Class IV. The K-S test showed that the results were confirmed to normal distribution and Pearson correlation analysis exhibited that the results of these two methods had a significant positive correlation. The two results had the same tendency generally. Depending on the results, the water quality in the North Canal River Basin

* 北京市水生态监测调查与研究项目资助. 2016-09-14 收稿;2017-02-07 收修改稿. 顾晓昀 (1992 ), 女, 硕士 研究生;E-mail: guxiaoyun92@163.com.

** 通信作者;E-mail: zxxu@ bnu.edu.cn. 
was poor. The main stream was better than the tributaries and the upstream was better than the downstream. The water quality in the upstream of the Wenyu River, the downstream of the Ba River, the upstream of the Tonghui River and the Liangshui River were poor while the headwater of the Wenyu River and the upstream of the Ba River were excellent. The result of comprehensive water quality identification index was a little better than that of Biotic Index. This was attributed to the reason that the two assessment methods focused on different spatial and temporal scales. In the North Canal River Basin with high urbanization level and strong human disturbance, the complex water ecological condition could be better understood with both assessment methods at the same time. Keywords: Macroinvertebrates; community structure; Biotic Index; comprehensive water quality identification index; water quality assessment; North Canal River

水环境质量评价是水环境管理的一项基础性工作, 合理的评价方法可以准确描述河流的水质状况, 以 满足水环境管理和决策需要 ${ }^{[1-4]}$. 在我国城市河流水质评价研究中, 综合水质标识指数法具有较好的评价效 果和应用前景 ${ }^{[5-6]}$. 随着近年来河流健康状况的不断恶化, 水环境污染物质的日益复杂,传统的基于水体理 化因子的评价方法对水环境质量的反映较为片面,已不能够满足河流水质评价的要求.

基于水生生物的水质评价方法不仅能反映环境中各种污染因子对生物的综合作用, 而且能反映水体中 污染物的累积效应, 对水环境的长期影响作出反应 ${ }^{[7-8]}$, 具有传统方法所不可替代的优越性. 在水质生物评 价的研究中, 水生生物的选择是一项重要环节 ${ }^{[9]}$. 底栖动物作为维系水生态系统结构和功能的重要部分, 对 水生态系统中营养物质的分解和循环有显著影响 ${ }^{[0]}$. 底栖动物具有生活场所相对固定、生命周期长、对环 境变化敏感, 且缺乏有力回避等特点, 其群落结构可较好地反映河流水环境健康状况, 因而常被用来作为水 生态系统健康的指示生物 ${ }^{[11-13]}$. 在基于底栖动物的水质评价研究中, $B I$ (Biotic Index) 指数的应用较为广泛, 国内相关研究主要集中在辽宁省 ${ }^{[13]}$ 、安徽省南部山区 ${ }^{[7]}$ 、江苏省南京秦淮河 ${ }^{[14]}$ 和长江三角洲地区 ${ }^{[8]}$ 等, 在 这些地区均取得了较好的评价效果.

北运河水系覆盖北京市 9 个区, 北京市 $70 \%$ 以上人口在此流域内工作生活, 是北京市人口最多、城市化 水平最高的流域. 因此, 北运河水系是受人类活动干扰较强烈的地区, 水环境状况相对复杂. 近年来, 北运河 水环境质量的相关研究主要集中在水质指数 ${ }^{[15]}$ 、污染物时空变化特征 ${ }^{[16]}$ 、浮游动植物的多样性指数和均匀 度指数 ${ }^{[17-18]}$ 、底栖动物的 Trent 指数和 $I B I$ 指数 ${ }^{[19-20]}$ 等方面. 这些研究多数基于水体理化因子或水生生物中 的一个类群 ${ }^{[6,21-23]}$, 这使得评价结果难以全面反映环境质量现状, 而同时采用两种评价方法并进行比较的研 究相对较少 ${ }^{[24-26]}$.

基于以上背景, 本文以北京市北运河水系为例, 从水质和水生生物两个方面出发,采用综合水质标识指 数法和底栖动物 $B I$ 指数法评价北运河水系的水质状况, 并将两种评价结果进行对比, 以期从不同的角度认 识北运河水系的水环境健康状况,使得评价结果更具合理性, 同时为改善和管理北运河水系的水生态系统 健康状况提供基础数据.

\section{1 研究区域及方法}

\section{1 研究区域}

北京市地处海河流域,辖区内从东到西分布有蓟运河、潮白河、北运河、永定河和大清河五大水系, 北运河 水系是唯一发源于北京市境内的水系 ${ }^{[27]}$ (图 1). 北运河地处潮白河和永定河之间, 发源于北京市昌平县燕山 南麓, 北京市境内干流包括上游温榆河段 (图 2). 北运河上游自沙河闸起,沙河闸上有南沙河、北沙河和东沙河 汇人, 自沙河闸向东及东南流至通州,先后接纳了萄沟、清河、坝河、通惠河等. 北运河下游始于通州北关闸,沿 途有凉水河和港沟河汇人, 于通州杨洼闸出北京市界, 凤河和龙河在北京市界外人北运河 ${ }^{[28]}$. 北运河水系属暖 温带半干旱半湿润季风气候, 地形以平原为主 (图 1), 植被类型主要是暖温带落叶阔叶林, 年平均气温为 $11 \sim$ $12^{\circ} \mathrm{C}$, 多年平均降雨量 $643 \mathrm{~mm}$, 降雨主要集中在 6-9 月, 多年平均径流量为 $4.81 \times 10^{8} \mathrm{~m}^{3[29]}$. 作为北京市的主 要排洪通道, 北运河每年承纳北京市区约 $90 \%$ 的排洪量 ${ }^{[30]}$.

\section{2 研究方法}

1.2.1 底栖动物样品采集与鉴定 2015 年 5 月, 在北运河水系设立了 33 个采样点开展底栖动物调查 (图 2). 为了使采样点尽可能准确反映现实的水环境质量状况, 布点原则主要依据水系内的人类活动干扰强度, 即 

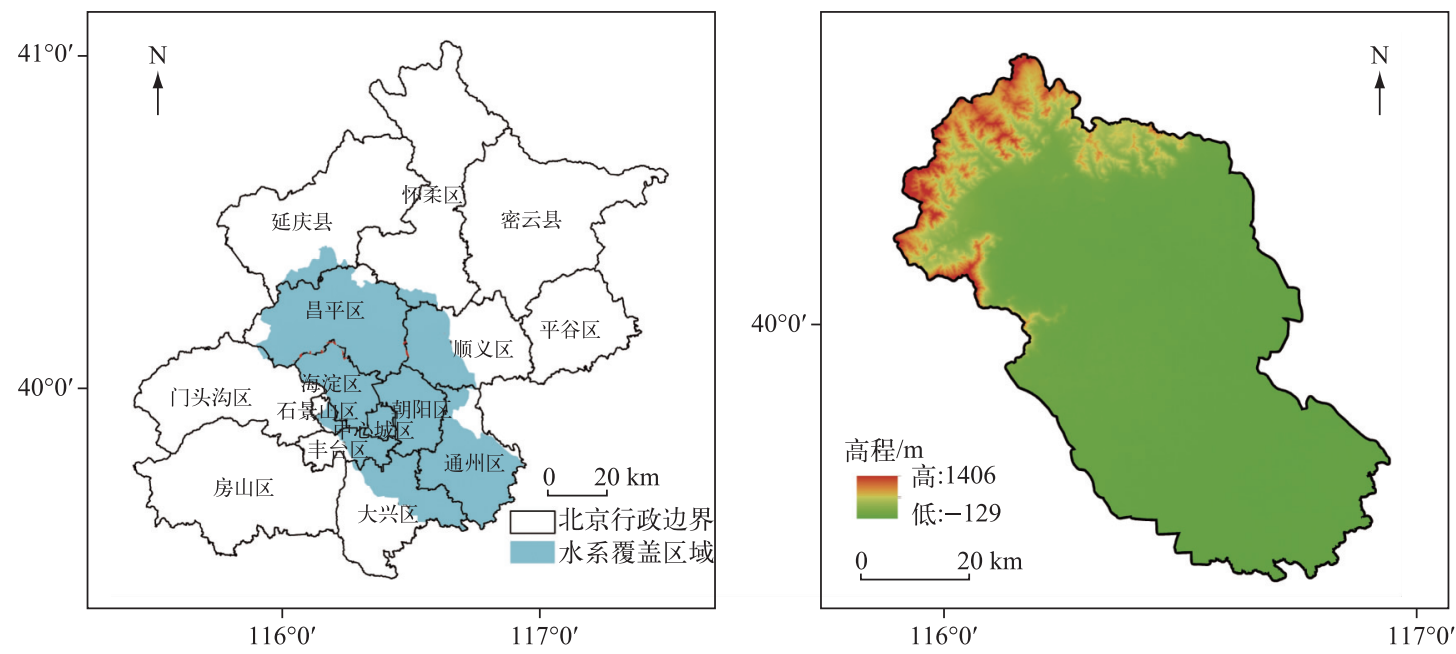

图 1 北运河水系区位和高程

Fig. 1 Location and elevation of the North Canal River Basin

人类活动干扰越强, 采样点越密集. 此外, 采样点要能够代表点位附近河段尺度的水域自然特征. 由于水系 内昌平区、海淀区、朝阳区和中心城区的人口密度较大, 人类活动干扰较强, 因此采样点大多集中在这几个 区内. 用 MAGELLAN 全球定位系统 (eXplorist-200) 记录采样点的经纬度. 在以所选采样点为中心 $50 \mathrm{~m}$ 为 半径的圆形区域内,使用 $1 / 16 \mathrm{~m}^{2}$ 的彼得森采泥器采集 1 个泥样,将采集到的泥样用 60 目的网篎篮洗,并转 人白磁盘中. 在采样现场用人工挑拣的方法, 将肉眼可见的底栖动物样品转人 $200 \mathrm{ml}$ 的广口塑料瓶中, 并加 人 $95 \%$ 的酒精溶液保存待检 ${ }^{[9]}$. 转人实验室后, 依据相关的文献资料 ${ }^{[31-34]}$, 在显微镜或解剖镜下进行分类和 计数, 样品尽量鉴定到属或种.

1.2.2 水体理化因子测定 采用便携式水质监测仪 (YSI 85) 现场测定溶解氧 (DO) 浓度. 根据 GB 3838-

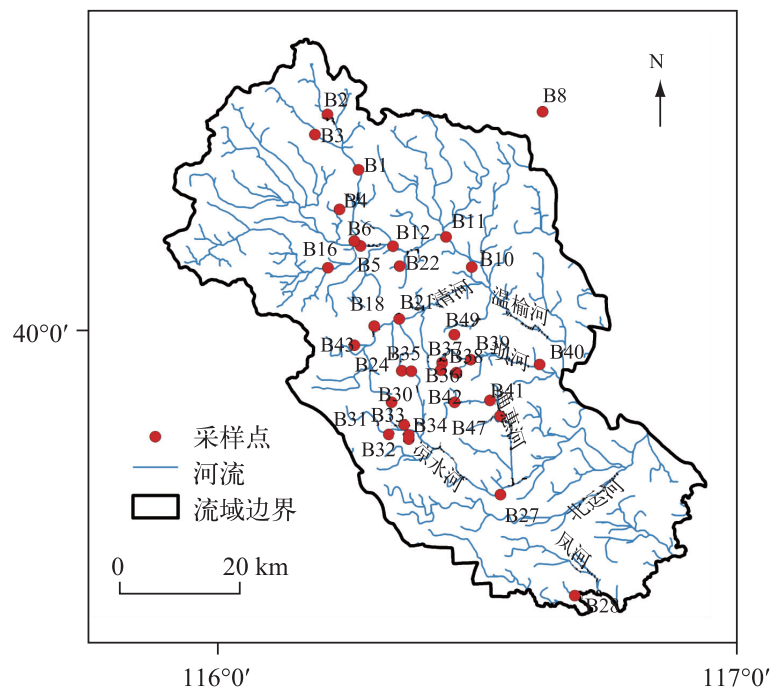

图 2 北运河水系采样点分布

Fig.2 Distribution of sampling sites in the North Canal River Basin
2002 《地表水环境质量标准》, 在实验室内测 定水样的氨氮 $\left(\mathrm{NH}_{3}-\mathrm{N}\right)$ 、五日生化需氧量 $\left(\mathrm{BOD}_{5}\right)$ 、高锰酸盐指数 $\left(\mathrm{COD}_{\mathrm{Mn}}\right)$ 、总氮 $(\mathrm{TN})$ 、 总磷 (TP) 浓度.

1.2.3 底栖动物 $B I$ 指数法 底栖动物 $B I$ 指数 是利用水体中指示生物的种类、数量及其对水 污染的敏感性建立的表示水环境质量的数 值 ${ }^{[14]}$, 该指数于 1972 年由 Chutter 最先提出. $B I$ 指数的计算公式为:

$$
B I=\sum_{i=1}^{n} \frac{n_{i} \cdot t_{i}}{N}
$$

式中, $n_{i}$ 为第 $i$ 个分类单元 (通常为属级或种 级) 的个体数; $t_{i}$ 为第 $i$ 个分类单元的耐污值; $N$ 为样本总个体数. 底栖动物的耐污值参考文 献 $[7,35]$.

参考 Karr 等 ${ }^{[36-39]}$ 使用的水质生物评价指 数值与分值的转换方法, 计算 $B I$ 指数水质评 价分级标准. 具体选择方法为: 应用所有样点 的 $B I$ 值, 通过频数分析, 以 $5 \%$ 分位数对应的 
值作为标准 ${ }^{[7-8]}$, 小于该值表示水质最清洁 ( I ), 对大于该值至最大值的分布范围四等分, 分值从小到大依 次分别代表清洁 ( II )、轻污染 ( III)、中污染 (IV) 和重污染 (V).

1.2.4 综合水质标识指数法 综合水质标识指数法以单因子水质标识指数法为基础, 不仅可以对河流 $\mathrm{I} \sim \mathrm{V}$ 类水体进行评价, 也可以对劣 $\mathrm{V}$ 类水体进行详细评价和比较 ${ }^{[6]}$, 将恶臭对水质的不利影响考虑其中, 适用范 围广, 且易于操作施行 ${ }^{[40]}$, 是目前最优选的评价方法之一.

综合水质标识指数可以完整反映综合水质类别、水质状况以及与水环境功能区类别的比较结果等相关 信息,由同济大学徐祖信提出, 其计算方法主要分为 2 部分 ${ }^{[5,40]}$.

1) 单因子水质标识指数的计算:

单因子水质标识指数 $P$ 由一位整数、小数点后二位或三位有效数字组成,可表示为:

$$
P_{i}=X_{1} \cdot X_{2} X_{3}
$$

式中, $X_{1}$ 为第 $i$ 项水质指标的水质类别; $X_{2}$ 为实测数据在 $X_{1}$ 类水质变化区间中所处的位置, 根据公式按四舍 五人原则计算; $X_{3}$ 为水质类别与功能区划设定类别的比较结果.

2) 综合水质标识指数的计算:

综合水质标识指数由一位整数和三位或四位小数位组成, 其结构为:

$$
I_{\mathrm{wq}}=X_{1} \cdot X_{2} X_{3} X_{4}
$$

式中, $X_{1}$ 为河流总体的综合水质类别; $X_{2}$ 为综合水质在 $X_{1}$ 类水质变化区间内所处的位置; $X_{3}$ 为参与综合水质评 价的水质指标中, 劣于目标水环境功能区的单项指标个数; $X_{4}$ 为综合水质类别与水体功能区类别的比较结果.

由于本研究只需用到 $X_{1}$ 和 $X_{2}$ 的计算,故这里对于 $X_{3}$ 和 $X_{4}$ 的计算不作具体介绍. $X_{1} \cdot X_{2}$ 的计算公式为:

$$
X_{1} \cdot X_{2}=\frac{1}{m} \sum\left(P_{1}^{\prime}+P_{2}^{\prime}+\cdots+P_{m}^{\prime}\right)
$$

式中, $m$ 为参加综合水质评价的水质单项指标个数; $P_{1}^{\prime} 、 P_{2}^{\prime} 、 P_{m}^{\prime}$ 分别为第 $1 、 2 、 m$ 个水质因子对应的单因子水 质标识指数中的一位整数和小数点后第一位.

根据综合水质标识指数法的水质评价分级标 准 (表 1) 可以方便快捷地对水质状况作出较准确 的评价.

1.2.5 相关分析 针对底栖动物 $B I$ 指数法和综合 水质标识指数法的水质评价结果, 用 SPSS 17.0 软 件进行相关分析,得到相关系数 $r$ 和显著性水平 $P$ 值. 两种评价结果在分析之前均先进行 Kolmogorov-Smirnov 正态检验, 并根据检验结果判 断相关分析所用方法.

\section{2 结果}

\section{1 底栖动物群落结构}

北运河水系共鉴定出底栖动物 23 种 (附表), 隶属于 3 门 4 纲 6 目 11 科 11 属, 以水生昆虫和软体动物 为主. 其中水生昆虫 10 种, 占 $43.5 \%$; 软体动物 11 种, 占 $47.8 \%$; 环节动物 2 种, 占 $8.7 \%$. 水生昆虫主要由双 翅目摇蚊组成, 常见种为溪流摇蚊 (Chironomus riparius). 软体动物常见种为梨形环棱螺 (Bellamya purificata)、狭耳夢卜螺 (Radix tagotis) 和拟沼螺 (Assimineidae sp.) (附表). 北运河整个水系底栖动物群落结 构单一,物种种类数较少, 且呈现中心低、南北高的分布趋势 (图 3).

\section{2 基于底栖动物 $B I$ 指数法的水质评价}

根据前述的 $B I$ 指数水质评价分级标准确定方法, 本研究计算得到的 $B I$ 指数最小值为 2.50 , 最大值为 $9.60,5 \%$ 分位数为 2.50 , 故 $B I$ 指数的水质评价分级标准如表 2 所示.

在北运河水系设立的 33 个点位中, 2 个为清洁 (II), 占总点位的比例为 $6 \% ; 7$ 个为轻污染 ( III), 占 $21 \% ; 8$ 个为中污染 $(\mathrm{IV})$, 占 $24 \%$; 16 个为重污染 (V), 占 $48 \%$; 无最清洁 ( I ) 水质的点位 (图 $4 \mathrm{a}$ ). 从全流 
表 2 底栖动物 $B I$ 指数法的水质评价分级标准

Tab.2 Water quality classification criterion on the basis of Biotic Index of macroinvertebrates

\begin{tabular}{cccccc}
\hline 评价依据 & 最清洁 $($ I ) & 清洁 $($ II $)$ & 轻污染 $($ III $)$ & 中污染 $($ IV $)$ & 重污染 $(\mathrm{V})$ \\
\hline 底栖动物 $B I$ 指数 & $<2.50$ & $2.50 \sim 4.28$ & $4.28 \sim 6.07$ & $6.07 \sim 7.86$ & $>7.86$ \\
\hline
\end{tabular}

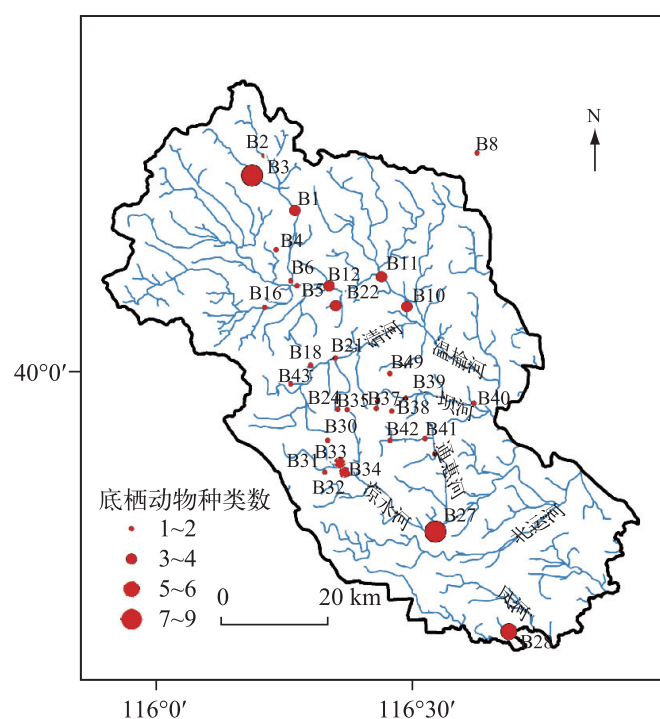

图 3 北运河水系底栖动物种类数分布

Fig.3 Spatial pattern of species richness on macroinvertebrates in the North Canal River Basin

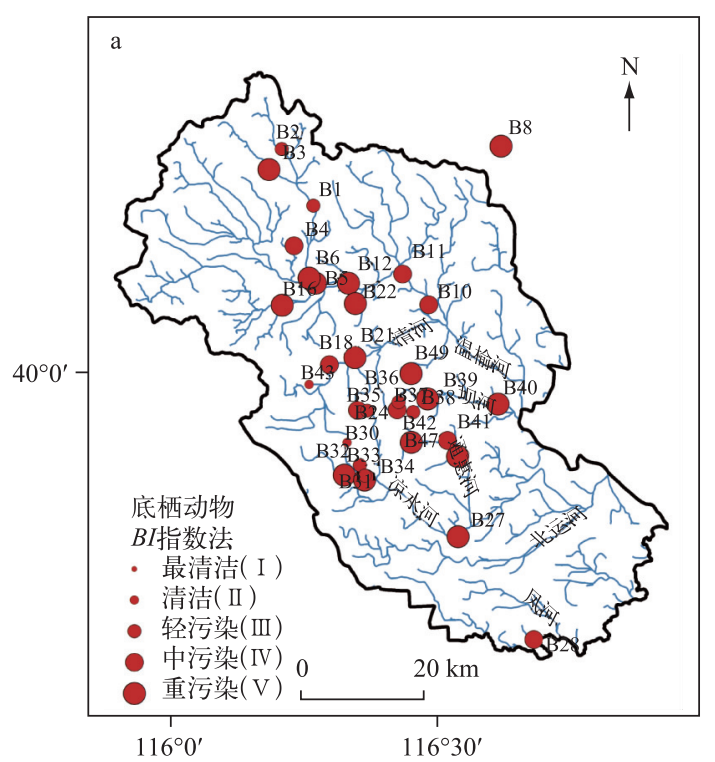

域来看,总体水质状况较差, 基本呈现为干流的水质状 况优于支流, 上游的水质状况优于下游. 其中, 温榆河上 游、坝河下游、通惠河上游和凉水河的水质状况较差, 水 质等级多为中污染 ( IV) 和重污染 $(\mathrm{V})$, 而温榆河源头和 坝河上游的水质状况较好, 永定河引水渠下段 (B30)、 团城湖 (B43) 的水质状况均较其他支流好.

\section{3 基于综合水质标识指数法的水质评价}

根据前述的综合水质标识指数法的水质评价分级 标准, 北运河水系的 33 个点位中, I类水有 10 个, 占总 点位的比例为 $30 \%$; III类水有 4 个, 占 $12 \% ; \mathrm{IV}$ 类水有 3 个,占 $9 \% ; \mathrm{V}$ 类水有 3 个, 占 $9 \%$; 劣 $\mathrm{V}$ 类但不黑臭有 7 个,占 $21 \%$; 劣 V类并黑臭有 6 个, 占 $18 \%$; 无I类水水质 的点位 (图 4b). 北运河水系整体的水质状况为一般, 基 本格局呈现为干流的水质状况优于支流, 上游的水质状 况优于下游. 水质状况较差的河段包括温榆河中游、坝 河下游、通惠河上游、凉水河和凤河, 鲁疃闸 (B10)、东 玉河(B22)、沙窝(B40)、南花园 (B47)、马驹桥 (B27)、 凤河营闸 (B28) 的水质状况最差, 温榆河源头和坝河上 游的水质状况集中较好.

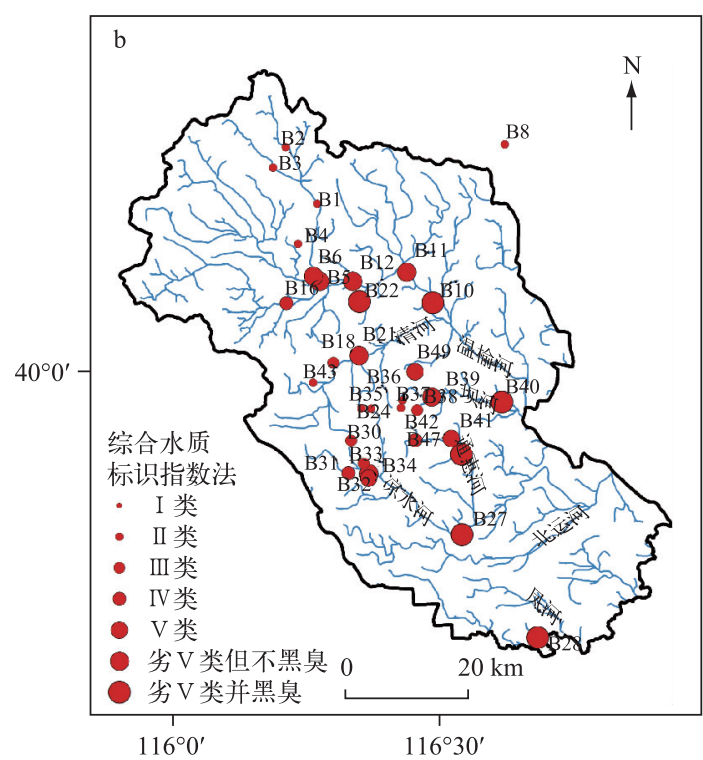

图 4 北运河水系两种水质评价方法的评价类别分布

Fig.4 Assessment clasfication distribution of two water quality assessment methods in the North Canal River Basin 


\section{4 两种水质评价结果的对比}

底栖动物 $B I$ 指数法和综合水质标识指数法的水质评价结果如表 3 所示, 两种评价结果存在一定的相似 性. 对两种评价结果分别进行 K-S 正态检验, 发现 $B I$ 指数评价得分 $(Z=0.895, P=0.400)$ 和综合水质标识指 数评价得分 $(Z=0.812, P=0.524)$ 均符合正态分布. 对两种评价结果进行 Pearson 相关分析, 发现两组分值呈 显著正相关 $(r=0.573, P<0.001)$, 表明底栖动物 $B I$ 指数法与综合水质标识指数法的评价结果具有较高的一 致性.

表 3 北运河水系两种水质评价结果的对比

Tab.3 Comparison between the two water quality assessment results in the North Canal River Basin

\begin{tabular}{|c|c|c|c|c|c|}
\hline 点位 & 底栖动物 $B I$ 指数法 & 综合水质标识指数法 & 点位 & 底栖动物 $B I$ 指数法 & 综合水质标识指数法 \\
\hline B1 & 轻污染( III ) & II 类 & $\mathrm{B} 30$ & 清洁( II ) & III类 \\
\hline B2 & 轻污染 ( III ) & II 类 & B31 & 重污染 ( V) & IV 类 \\
\hline B3 & 重污染 ( V) & II 类 & B32 & 轻污染 ( III ) & IIII类 \\
\hline B4 & 中污染 ( IV ) & II 类 & B33 & 轻污染 ( III ) & 劣 $V$ 类但不黑臭 \\
\hline B5 & 重污染 ( V) & 劣 $V$ 类但不黑臭 & B34 & 重污染 ( V) & $\mathrm{V}$ 类 \\
\hline B6 & 重污染 ( V) & 劣 $V$ 类但不黑臭 & B35 & 轻污染 ( III ) & II 类 \\
\hline B8 & 重污染 ( V) & II 类 & B36 & 轻污染 ( III ) & II 类 \\
\hline B10 & 中污染 ( IV ) & 劣 V 类并黑臭 & B37 & 中污染 ( IV ) & II 类 \\
\hline B11 & 中污染 ( IV ) & 劣 V 类但不黑臭 & B38 & 轻污染 ( III ) & III类 \\
\hline B12 & 重污染 ( V) & 劣 V 类但不黑臭 & B39 & 重污染 ( V) & 劣 V 类但不黑臭 \\
\hline B16 & 重污染( V) & IV 类 & B40 & 重污染 ( V) & 劣 V 类并黑臭 \\
\hline B18 & 中污染 ( IV ) & III类 & B41 & 中污染 ( IV ) & $\mathrm{V}$ 类 \\
\hline B21 & 重污染( V) & 劣 V 类但不黑臭 & B42 & 重污染 ( V) & IV类 \\
\hline B22 & 重污染( V) & 劣 V 类并黑臭 & B43 & 清洁( II ) & II 类 \\
\hline B24 & 中污染 ( IV ) & II 类 & B47 & 重污染 ( V ) & 劣 $V$ 类并黑臭 \\
\hline B27 & 重污染 ( V) & 劣 V 类并黑臭 & B49 & 重污染 ( V) & $\mathrm{V}$ 类 \\
\hline B28 & 中污染 ( IV ) & 劣 V 类并黑臭 & & & \\
\hline
\end{tabular}

\section{3 讨论}

北运河水系地处北京市中心区域, 从西北方向横跨北京市至东南方向, 人口稠密, 城市化水平高, 是北 京市境内受人类活动干扰最强烈的水域之一.

有研究表明, 水生昆虫摇蚊主要以细菌和藻类为食, 对水质净化有重要作用, 而寡毛类喜欢生活在腐殖 质丰富、有机污染严重的水域中, 是水质污染程度的重要指示生物 ${ }^{[32]}$. 高彩风 ${ }^{[41]}$ 对北运河水系底栖动物的 调查结果显示, 该水系的底栖动物有 17 种, 以寡毛类和软体动物为主, 水生昆虫种类极少, 且典型的寡毛类 如霍甫水丝蚓 (Limnodrilus hoffmeisteri)、克拉伯水丝蚓 (Limnodrilus claparedianus)、管水蚓 (Aulodrilus bretscher) 和苏氏尾鰓蚓 (Branchiura sowerbyi) 均是该水系的优势种. 本次调查中共鉴定出底栖动物 23 种, 以 水生昆虫和软体动物为主, 且呈现出群落结构单一的特点. 与高彩风 ${ }^{[41]}$ 的调查结果相比, 本次调查中底栖 动物的种类数有所增加, 且群落组成呈现出水生昆虫种类数增加, 寡毛类种类数减少的态势, 可以推测北运 河水系的水环境质量得到了一定程度的改善. 由于葟毛类是水体有机污染的重要指示物种 ${ }^{[42]}$, 因此葟毛类 的减少还可以间接推测北运河水系水质变好的贡献因素之一是有机污染的缓解, 这与综合水质标识指数法 的评价结果大体一致.

通过分析综合水质标识指数法和底栖动物 $B I$ 指数法的评价结果, 可以发现, 北运河水系中水质状况集 中较好的区域为坝河上游,这可能与近些年北京市政府着手治理坝河, 兴建坝河湿地公园, 重建城市景观河 道有关, 这些措施都使得坝河附近的水生态环境优化, 水质状况得到好转 ${ }^{[43]}$. 温榆河作为北运河上游, 自沙 河水库至通州区北关拦河闸, 跨越了北京市昌平区、顺义区和通州区, 其中, 昌平区的东南部处于城乡结合 部, 人口增长较快, 且沿线尚未铺设污水管线, 大量的生活污水未经处理就直接排人河道, 造成该地区成为 
温榆河水质状况相对较差的河段 ${ }^{[44]}$. 总体来看, 两种水质评价方法得到的北运河水系水质状况相近, 均为 中污染和重污染, 这与高彩风 ${ }^{[41]}$ 通过浮游植物、浮游动物和底栖动物的生物多样性指数得到的春季水质在 中一重污染之间的结论一致, 与张光锦通过层次分析法得到的北运河生态状况总体为亚健康的结论大体 一致 ${ }^{[45]}$.

无论采用哪种水质评价方法, 其目的都是了解水体水质状况, 衡量水环境健康程度, 从而有目的地管理 和保护水资源, 因此底栖动物 $B I$ 指数法和综合水质标识指数法应该是相辅相成的 ${ }^{[24]}$. 在本研究中, 两种评 价结果总体趋势相同, 但个别点位仍存在差异, 具体表现为综合水质标识指数法的评价结果稍优于底栖动 物 $B I$ 指数法, 这与周笑白等 ${ }^{[24]}$ 和焦柯伟等 ${ }^{[46]}$ 的研究结果较一致. 依据周笑白等在太湖的研究成果, 基于水 体理化因子和水生生物的水质评价方法在时空尺度上存在差异 ${ }^{[24]}$.

从时间尺度来看, 水体理化因子表征的是采样点瞬时的水环境质量, 其值受温度、水量、风力等环境因 素影响较大, 因此基于水体理化因子的水质评价结果是瞬时水质状况. 相比之下, 底栖动物的种类和数量表 征的是采样点长期的水环境综合质量, 是在长时间的累积效应下逐步形成的, 因此基于生物的水质评价结 果是长期的平均水质状况. 近年来, 随着生活水平的提高, 人们对于生态环境也提出了更高的要求. 2001 年, 天津市开始实施北运河综合治理工程 ${ }^{[4]} ; 2008$ 年, 北京市首次通过了《北运河流域水系综合治理规划》 ${ }^{[48]}$. 这些措施使得北运河水系的整体水环境质量有了显著改善, 因此水质状况出现好转. Bertrand Millet 等的研 究表明, 当环境发生一定变化时,生物并不会作出即时响应,生物对环境变化的响应通常具有滞后性 ${ }^{[49]}$. 北 运河水系地处北京市中心, 人口众多, 经济发达,生活和工业废污水排放量大,水环境变化剧烈, 栖息生境遭 到严重破坏, 不利于底栖动物的附着; 底栖动物在水生态系统中等级较高, 移动能力较弱, 只能被动耐受环 境中的变化 ${ }^{[50]}$; 北运河水系的地形以平原为主, 地势平坦, 河流的人工渠道化现象严重, 导致流域内水体流 动缓慢, 更新周期较长, 不利于底栖动物快速感知水环境的变化 ${ }^{[51]}$. 这些因素都导致生物健康状况对水质 状况变化的反映具有滞后性, 因此基于生物的水质评价结果并未表现出较大转变, 仍然劣于基于水体理化 因子的水质评价结果.

从空间尺度来看, 基于水体理化因子的水质评价主要关注水体中的营养盐和污染物质浓度是否超过环 境阈值 ${ }^{[24]}$, 因此其评价结果仅针对水体本身. 而长期生活在水环境中的底栖动物, 不仅反映了水体质量, 还 体现了生境质量 (底质、栖境复杂性、植被多样性、人类活动强度、土地利用方式等), 因此其评价结果涉及的 范围更广. 水质生物评价结果劣于基于水体理化因子的水质评价结果说明, 虽然北运河水系的水质状况近 些年有所改善, 但水生态系统的整体质量并未显著提高. 综上所述, 基于水体理化因子的方法适宜评价短时 间内的单一水质状况, 而基于水生生物的方法适宜评价长时间内的综合水质状况, 这两种评价方法能从不 同角度反映水环境质量,满足管理部门对水环境进行保护和治理的不同尺度需求.

对于城市河流, 单纯从某一个角度评价难以全面衡量其复杂多变的水环境质量, 考虑多方面因素、运用 多种方法、整合不同时空尺度, 将会是未来城市河流水质评价的发展趋势. 此外, 本研究的底栖动物耐污值 是从文献中获取的, 有研究表明, 耐污值本身会因底栖动物所处地域的差异而发生改变 ${ }^{[52]}$, 因此水质生物评 价结果可能会受耐污值准确性的影响. 关于如何确定北运河水系的底栖动物耐污值, 有待于进一步的研究.

\section{4 参考文献}

[ 1 ] Yin Hailong, Xu Zuxin. Comparative study on typical river comprehensive water quality assessment menthods. Resources and Environment in the Yangtze Basin, 2008, 17(5): 729-733. [尹海龙, 徐祖信. 河流综合水质评价方法比较研究. 长江流域资源与环境, 2008, 17(5): 729-733.]

[ 2 ] Lu Weijun, Zhang Tao. Comparison and analysis of several appraisal methods for river water quality. Environmental Science and Management, 2009, 34(6): 174-176. [陆卫军, 张涛. 几种河流水质评价方法的比较分析. 环境科学与管理, $2009, \mathbf{3 4}(6): 174-176$.

[ 3 ] Zhu Wei, Xia Ting, Jiang Mouyu et al. Comprehensive assessment of water environment for urban stream. Advances in Water Science, 2007, 18(5): 736-744. [ 朱伟, 夏霆, 姜谋余等. 城市河流水环境综合评价方法探讨. 水科学进展, $2007,18(5): 736-744$.

[ 4 ] Chen Yanqing, Meng Wei, Wu Xuefang et al. Ambient water quality criteria system in the United States. Research of Envi- 
ronmental Sciences, 2011, 24(4) : 467-474. DOI:10.13198/j.res.2011.04.107.chenyq.016. [陈艳卿, 孟伟, 武雪芳等. 美国水环境质量基准体系. 环境科学研究, 2011, 24(4) : 467-474.]

[ 5 ] Xu Zuxin. Comprehensive water quality identification index for environmental quality assessment of surface water. Journal of Tongji University: Natural Science, 2005, 33(4) : 482-488. [徐祖信. 我国河流综合水质标识指数评价方法研究. 同济大学学报:自然科学版, 2005, 33(4): 482-488.]

[ 6 ] Wu Wei, Xu Zongxue, Yu Songyan. Water quality assessment and analysis for the Wei River Basin. Journal of Beijing Normal University: Natural Science, 2013, 49(2/3) : 275-281. [武玮, 徐宗学, 于松延. 渭河流域水环境质量评价与 分析. 北京师范大学学报: 自然科学版, 2013, 49(2/3): 275-281.]

[ 7 ] Wang Beixin. Water quality bioassessment using benthic macroinvertebrates [Dissertation]. Nanjing: Nanjing Agricultural University, 2003. [王备新. 大型底栖无脊椎动物水质生物评价研究 [学位论文]. 南京: 南京农业大学, 2003.]

[ 8 ] Qin Chunyan. Quantitative tolerance values for common stream benthic macroinvertebrate and water quality classification use of biotic index (BI) in Yangtze River Delta [Dissertation]. Nanjing: Nanjing Agricultural University, 2013. [秦春 燕. 长江三角洲淡水底栖动物耐污值修订和 BI 指数水质评价分级研究 [ 学位论文]. 南京: 南京农业大学, 2013.]

[ 9 ] Yin Xuwang, Li Qingnan, Zhu Meihua et al. Community structure and biological integrity of macroinvertebrates in the wet and dry seasons of Wei River basin, China. Acta Ecologica Sinica, 2015, 35 (14) : 4784-4796. DOI: 10. 5846/ stxb201311112712. [殷旭旺, 李庆南, 朱美华等. 渭河丰、枯水期底栖动物群落特征及综合健康评价. 生态学报, 2015, 35(14) : 4784-4796.]

[10] Jiang Jing, Wen Fangni, Gu Peng et al. Community structure of macrozoobentos and bioassessment of water quality in Hujiaxi Stream of Qingjiang River Basin, Hubei Province. J Lake Sci, 2009, 21(4) : 547-555. DOI:10.18307/2009.0414. [江晶, 温芳妮, 顾鹏等. 湖北清江流域胡家溪大型底栖动物群落结构及水质评价. 湖泊科学, 2009, 21 (4): 547-555. ]

[11] Dai Jicui, Ni Jinren. Roles of benthos in the aquatic ecosystem health assessment. Ecology and Environment, 2008,17 (5)：2107-2111. [ 戴纪翠, 倪晋仁. 底栖动物在水生生态系统健康评价中的作用分析. 生态环境, 2008, 17(5)： 2107-2111.]

[12] Wang Beixin, Yang Lianfang. Bioassessment of Qinhuai River using a river biological index. Acta Ecologica Sinica, 2003, 23(10) : 2082-2091. [王备新, 杨莲芳. 用河流生物指数评价秦淮河上游水质的研究. 生态学报, 2003, 23(10): 2082-2091.]

[13] Xing Shuwei, Wang Juncai, Ding Zhenjun et al. Large benthonic invertebrates' tolerance values and water quality evaluation in Liaoning Province. Environmental Protection Sciences, 2013, 39(3): 29-33. [邢树威, 王俊才, 丁振军等. 辽宁 省大型底栖无脊椎动物耐污值及水质评价. 环境保护科学, 2013, 39(3): 29-33.]

[14] Zhang Yueping. A study on tolerance value of benthic macroinvertebrates and biotic index in Jiangsu Province [Dissertation]. Nanjing: Nanjing Agricultural University, 2006. [张跃平. 江苏大型底栖无脊椎动物耐污值、BI 指数及水质生 物评价研究 [学位论文]. 南京: 南京农业大学, 2006.]

[15] Jing Hongwei, Zhang Zhigang, Guo Jing. Water pollution characteristics and pollution sources of Bei Canal river system in Beijing. China Environmental Science, 2013, 66(2) : 319-327. [荆红卫, 张志刚, 郭婧. 北京北运河水系水质污染特 征及污染来源分析. 中国环境科学, 2013, 66 (2) : 319-327.]

[16] Shan Baoqing, Jian Yuxiang, Tang Wenzhong et al. Temporal and spatial variation of nitrogen and phosphorus and eutrophication assessment in downstream river network areas of North Canal River Watershed. Environmental Science, 2012, 33 (2) : 352-358. [单保庆, 菅宇翔, 唐文忠等. 北运河下游典型河网区水体中氮磷分布与富营养化评价. 环境科学, $2012, \mathbf{3 3}(2): 352-358$.

[17] Liu Jing, Ma Keming, Zhang Yuxin et al. Summer phytoplankton community structure in the Wenyu River and its relationship with environmental factors. Journal of Hydroecology, 2015, 36 (5) : 22-28. DOI: 10. 15928/j. 1674-3075.2015.05. 004. [ 刘静, 马克明, 张育新等. 温榆河夏季浮游植物群落结构及其与环境因子的关系. 水生态学杂志, 2015, 36 (5) : 22-28.]

[18] Li Xuejun, Bao Zhanmeng, Gao Caifeng et al. Zooplankton investigation and water quality evaluation in Beiyun River. Chinese Journal of Ecology, 2014, 33(6) : 1559-1564. DOI:10.13292/j.1000-4890. 20140327. 005. [李学军, 鲍战猛, 高 彩风等. 北运河浮游动物调查及水质评价. 生态学杂志, 2014, 33(6) : 1559-1564.]

[19] Ren Shuzhi. Investigation on macroinvertebrate community and water quality in streams in Beijing area. Acta Scientiae Cir- 
cumstantiae, 1991 , 11(1) : 31-46. DOI: 10.13671/j.hjkxxb.1991.01.005. [任淑智. 北京地区河流中大型底栖无脊椎 动物与水质关系的研究. 环境科学学报, 1991, 11(1): 31-46.]

[20] Yang Liu, Li Yonghui, Wang Juncai et al. The assessment of river health using Benthic-Index of biotic integrity for Wenyu River. Acta Ecologica Sinica, 2012, 32(11) : 3313-3322. DOI: 10.5846/stxb201105160630. [杨柳, 李泳慧, 王俊才 等. 基于 B-IBI 指数的温榆河生态健康评价. 生态学报, 2012, 32(11) : 3313-3322.]

[21] Sheng Zhoujun, Sun Shiqun, Wang Jingcheng et al. Comprehensive evaluation of river water environmental quality based on the principal component analysis. Environmental Science and Management, 2007, 32(12): 172-175. [盛周君, 孙世 群, 王京城等. 基于主成分分析的河流水环境质量评价研究. 环境科学与管理, 2007, 32(12): 172-175.]

[22] Ma Taowu, Huang Qinghui, Wang Hai et al. The selection of benthic macroinvertebrate based multimetrics and preliminary establishment of biocriteria for the bioassessment of the water quality of Taihu Lake. Acta Ecologica Sinica, 2008, 28(3): 1192-1200. [马陶武, 黄清辉, 王海等. 太湖水质评价中底栖动物综合生物指数的笁选及生物基准的确立. 生态学 报, 2008, 28(3): 1192-1200.]

[23] Wu Zhaoshi, Cai Yongjiu, Chen Yuwei et al. Assemblage structure investigation of macrozoobenthos and water quality bioassessment of the main river systems in Taihu Basin. J Lake Sci, 2011, 23(5) : 686-694. DOI: 10.18307/2011.0504. [吴 召仕, 蔡永久, 陈宇炜等. 太湖流域主要河流大型底栖动物群落结构及水质生物学评价. 湖泊科学, 2011,23 (5) : 686-694.]

[24] Zhou Xiaobai, Zhang Ninghong, Zhang Yong et al. Preliminary study on the relationship between the water quality and the aquatic biological health status of Taihu Lake. Environmental Science, 2014, 35(1) : 271-278. DOI: 10. 13227/j. hjkx. 2014.01.070. [周笑白, 张宁红, 张咏等. 太湖水质与水生生物健康的关联性初探. 环境科学, 2014, 35(1): 271-278. ]

[25] Yang Liangjie, Lv Guanghan, Zhu Junquan et al. Characteristic of zooplankton community in Hengshan Reservoir and water quality assessment. Acta Hydrobiologica Sinica, 2014, 38(4) : 720-728. DOI: 10.7541/2014.102. [杨亮杰, 吕光汉, 竺俊全等. 横山水库浮游动物群落结构特征及水质评价. 水生生物学报, 2014, 38(4) : 720-728.]

[26] Wu Shirong, Xu Mengjia, Chen Yuqiao et al. Evaluation of eutrophication for the Hanshiqiao wetland based on water quality and plankton data. Acta Scientiae Circumstantiae, 2015, 35(2) : 411-417. DOI:10.13671/j.hjkxxb.2014.0875. [武士 蓉, 徐梦佳, 陈禹桥等. 基于水质与浮游生物调查的汉石桥湿地富营养化评价. 环境科学学报, 2015, 35(2): 411-417.]

[27] Guo Jing, Jin Hongwei, Li Jinxiang et al. Surface water quality of Beiyun Rivers Basin and the analysis of acting factors for the recent ten years. Environmental Science, 2012, 33(5): 1511-1518. DOI:10.13227/ j.hjkx.2012.05.025. [ 郭婧, 荆 红卫, 李金香等. 北运河系地表水近 10 年来水质变化及影响因素分析. 环境科学, 2012, 33(5): 1511-1518.]

[28] Liao Pingan. Water pollution situation and management technology analysis of Beiyun River Basin (Beijing section). Beijing Water, 2013, (1): 16-19. [廖平安. 北运河流域(北京段) 水污染态势与治理技术分析. 北京水务, 2013, (1) : 16-19.]

[29] Li Yan, Shan Baoqing, Chen Jing et al. Analysis of the oxygen-consuming features of pollutants in the North Canal Watershed, northern China. Journal of Safety and Environment, 2014, 14(5):311-315. [李延, 单保庆, 陈静等. 北运河流 域典型河流水体耗氧污染特征分析. 安全与环境学报, 2014, 14(5): 311-315.]

[30] Xu Xiaowei, Liu Dewen, Che Hongjun et al. The investigation and evaluation of water environment in Beiyun River. Haihe Water Resources, 2009, (2): 14-22. [许晓伟, 刘德文, 车洪军等. 北运河水环境调查与评价. 海河水利, 2009, (2) : 14-22.]

[31] Yang Tong. Fauna of China一Annelida一Hirudinea. Beijing: Science Press, 1996. [杨潼. 中国动物志一一环节动物 门一一蛭纲. 北京: 科学出版社, 1996.]

[32] Zhao Wen ed. Hydrobiology. Beijing: China Agriculture Press, 2005. [赵文. 水生生物学. 北京: 中国农业出版 社, 2005.]

[33] Merritt RW, Cummins KW, Berg MB eds. An introduction to the aquatic insects of North America. 4th Edition. Kendall: Hunt Publishing, 2008.

[34] Thorp JH, Covich AP eds. Ecology and classification of North American freshwater invertebrates, 2nd Edition. New York: Academic Press, 2001.

[35] Qin C, Zhou J, Cao Y et al. Quantitative tolerance values for common stream benthic macroinvertebrates in the Yangtze 
River Delta, Eastern China. Environmental Monitoring and Assessment, 2014, 186(9) : 5883-5895. DOI: 10.1007/s 10661-014-3826-2.

[36] Karr JR. Biological monitoring and environmental assessment: a conceptual framework. Environmental Management, 1987, 11(2) : 249-256.

[37] Gerritsen J. Additive Biological indices for resource management. Journal of the North American Benthological Society, 1995, 14(3) : 451-457.

[38 ] Barbour MT, Gerritsen J, Griffith GE et al. A framework for biological criteria for Florida streams using benthic macroinvertebrates. Journal of the North American Benthological Society, 1996, 15(2) : 185-211.

[39] Maxted JR, Barbour MT, Gerritsen J et al. Assessment framework for mid-Atlantic coastal plain streams using benthic macroinvertebrates. Journal of the North American Benthological Society, 2000, 19(1) : 128-144.

[40] Xu Zuxin. Single factor water quality identification index for environmental quality assessment of surface water. Journal of Tongji University: Natural Science, 2005, 33(3): 321-325. [徐祖信. 我国河流单因子水质标识指数评价方法研究. 同济大学学报: 自然科学版, 2005, 33(3): 321-325.]

[41] Gao Caifeng. Investigation of aquatic ecosystem and water quality evaluation in Beiyunhe River [Dissertation]. Xinxiang: Henan Normal University, 2012. [ 高彩凤. 北运河水系水生态调查与水质评价 [学位论文]. 新乡: 河南师范大 学, 2012.]

[42] Zhang Min, Cai Qinghua, Tang Tao et al. Macrobenthos community structure and its spatial distribution in Erhai watershed lakes. Chinese Journal of Ecology, 2011, 30( 8) : 1696-1702. DOI:10.13292/j.1000-4890.2011.0272. [张敏, 蔡庆华, 唐涛等. 洱海流域湖泊大型底栖动物群落结构及空间分布. 生态学杂志, 2011, 30(8): 1696-1702.]

[43] Wang Hui, Wang Yun. Water environment governance of Ba River. Beijing Water, 2009, (1) : 46-48. [王慧, 王望. 坝 河的水环境治理. 北京水务, 2009, (1): 46-48.]

[44] Zheng Fandong, Meng Qingyi, Wang Peijing et al. Study on status and improvement strategies of water environment in Wenyu River of Beijing. Beijing Water, 2007, (5) : 5-8. [郑凡东, 孟庆义, 王培京等. 北京市温榆河水环境现状及治理 对策研究. 北京水务, 2007, (5): 5-8. ]

[45] Zhang Guangjin. The research on ecosystem health evaluation and repairing methods of North Canal [Dissertation]. Tianjin: Tianjin University, 2009. [张光锦. 北运河生态健康评价及修复方法研究 [学位论文]. 天津: 天津大 学, 2009.]

[46] Jiao Kewei, Zhou Qixing. Health assessment of aquatic ecosystems in the Songhua River Basin on the basis of water quality and biological indicators. Chinese Journal of Ecology, 2015, 34 (6) : 1731-1737. DOI : 10.13292/ j. 1000-4890.2015. 0161. [焦珂伟, 周启星. 基于水质与生物指标的松花江流域水生态健康评价. 生态学杂志, 2015, 34 (6): 1731-1737.

[47] Yu Zhuomin. Brief introduction of comprehensive treatment engineering design in Beiyun River. Haihe Water Rources, 2005，(1)：19-20. [于卓敏. 北运河综合治理工程设计方案简述. 海河水利, 2005，(1) : 19-20.]

[48] Jin Guiqin, Sun Di, Wang Peijing et al. The mid-term assessment of comprehensive management in Beiyun River Basin. Beijing Water, 2014, (6) : 49-54. [ 金桂琴, 孙迪, 王培京等. 北运河流域水系综合治理开展中期评估. 北京水务, 2014, (6): 49-54.]

[49] Bertrand M, Philippe C. Wind-induced hydrodynamic control of the phytoplankton biomass in a lagoon ecosystem. Limnology and Oceanography, 1992, 37(1): 140-146.

[50] Zhang Min, Cai Qinghua, Sun Zhiyu et al. Effect and its time lags of water level fluctuations in Three Gorges Reservoir on the macroinvertebrates in a tributary bay. Chinese Journal of Applied and Environmental Biology, 2015, 21(1) : 101-107. DOI : 10.3724/SP.J.1145.2014.06021. [张敏, 蔡庆华, 孙志禹等. 三峡水库水位波动对支流库湾底栖动物群落的影 响及其时滞性. 应用与环境生物学报, 2015, 21(1): 101-107.]

[51] Lei Yu. Effects of turbulent fluctuation on the growth of algae and water environment [Dissertation]. Chongqing: Chongqing University, 2013. [雷雨. 紊流脉动对藻类生长及水环境的影响研究 [学位论文]. 重庆: 重庆大 学, 2013.]

[52] Zhao Rui, Gao Xin, Ding Sen et al. Tolerance values of macroinvertebrate taxa in Liao River basin. Acta Ecologica Sinica, 2015, 35(14) : 4797-4809. DOI: 10.5846/stxb201311082699. [赵瑞, 高欣, 丁森等. 辽河流域大型底栖动物耐污 值. 生态学报, 2015, 35(14) : 4797-4809.] 
附表 2015 年 5 月北运河水系底栖动物调查物种名录

Appendix Species list of macroinvertebrates occurred in the North Canal River Basin in May 2015

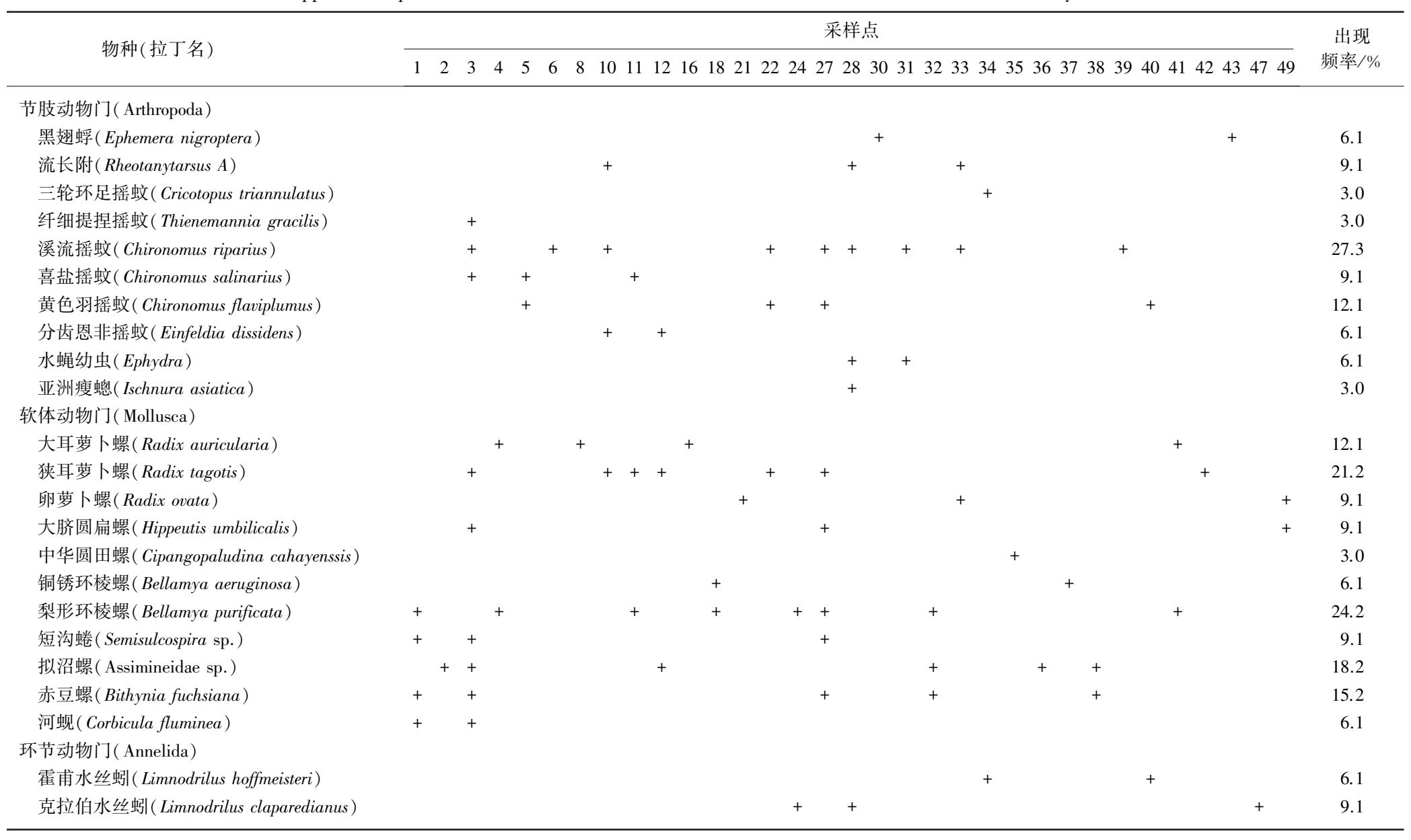

